\title{
Unequal geographies of the Italian tertiary education system. Mapping the disparities at regional scale
}

\author{
Giorgia Iovino* \\ * University of Salerno, Policom Department of Political Sciences and Communications giovino@ unisa.it
}

\begin{abstract}
In the last decade, the tertiary education system in Italy has shrinked and a larger heterogeneity has emerged among universities located in different areas of the country, with a strong concentration of increasingly scarce resources in a narrow and geographically concentrated number of institutions. The less developed areas, such as those in Southern Italy have been hit the most, in terms of enrolled students, academic staff, financial resources, courses offered.

In this work we investigate these issues by adopting a cartographic approach. We highlight these polarizing dynamics, disentangling the possible causes. We focus, particularly, on the role of new regulatory policies and the funding mechanisms based on performance indicators as producers of inequalities.
\end{abstract}

Keywords: tertiary education system; inequalities; Italy

\section{Introduction}

The tertiary education system represents a strategic asset for the growth of every nation: it qualifies human capital and promotes the dissemination of knowledge, feeds technological innovation, and facilitates social mobility, increases the competitiveness of the country system and the levels of income of its citizens. The impact of the university also has an important local dimension (Visco, 2014). Valero and Van Reenen (2016), in a research conducted on 15.000 universities located in different areas of the world ( 1.500 regions in 78 countries), highlight the benefits deriving from the presence of academic institutions, both in economic terms (per capita GDP growth) and cultural ones (more marked civic and prodemocratic attitudes, diffusion of a democratic culture, etc.). As the authors point out (Id, p.25), "the benefit of universities, is not confined to the region where they are built but 'spills over' to neighboring regions". In other words, the university can be a key driving force for economic, social and cultural growth for the territories in which it is located.

Italy, due to its mature manufacturing specialization and the presence of large lagging areas, would need more than other countries to invest in education and research to stimulate the emersion of innovative activities and the recovery of the weakest and most peripheral areas.

In this respect, the Italian situation appears to be extremely critical: within the OECD and EU the country ranks in the last places in public spending on tertiary education, despite the lowest number of graduates, after Romania. The scenario worsens further if we look at the territorial disparities within the system, which have grown sharply over the last decade.

Our guiding hypothesis is that the policy choices implemented since 2008 in a strongly recessive framework have favored a polarization of the increasingly scarce financial resources in a small and geographically concentrated number of institutions, with effects of great socio-spatial inequity. Rather than focusing on the promotion of a balanced and territorially widespread tertiary education system, it was decided to enhance territorial asymmetries, adopting questionable allocation criteria and reward mechanisms that have generated a lively and sometimes bitter debate within the academic world.

It is not within the scope of this work to discuss the Italian tertiary education reform process, nor to review the vast critical literature that has developed on the subject. However, it is worth highlighting, among the many critical issues identified, the use of spatially blinded allocative criteria, i.e. criteria based on weakly territorialized indicators of quality (Iovino, 2021).

In other words, the most attractive and performing universities were rewarded, without taking into account (or limitedly considering) the cultural and family background of students, the dynamism of the local labor market, the provision of urban services, income levels and university fees, the ability to mobilize public and private financial resources and so on. All these context variables inevitably affect the attractiveness and performance of the various institutions, benefiting those located in the richest and most dynamic regions.

Starting from these considerations, the work focuses on the territorial effects of these processes. Using data from different information sources (Anvur, MIUR-Student Registry, MIUR Decrees, etc.) we map the changes that occurred in the Italian tertiary education system, in order to highlight the downsizing of the whole system and its growing internal differentiation.

The analysis is carried out mainly on a regional scale but downscaling or upscaling are provided when useful, to better grasp trends and spatial patterns.

The paper is organized as follows: paragraph 2 looks at the Italian university system in a comparative perspective; paragraph 3 deals with the issue of internal territorial disparities of the system in terms of students, financial resources, academic staff, student mobility; in this section a classification of regional university systems is also 
proposed; paragraph 4 focuses on two key drivers of change in the geography of the tertiary education system: the recruitment policies and the establishment of so-called departments of excellence; finally, paragraph 5 presents some conclusive reflections.

\section{The Italian tertiary system in a comparative perspective}

The Italian university system, after a long expansion phase which begun in the 1960s, has experienced since 2008 a drastic downsizing in terms of enrolled students, teachers, technical-administrative staff, study programs and funding (Anvur, 2016; 2018). As remarked by Viesti (2016, p.4), this reduction has no comparison, for its intensity and steadiness in the rest of Europe and other advanced countries, in spite of the already considerably smaller dimensions of the Italian system.

Referring to more complete analyzes (Fondazione RES 2016; Viesti, 2017; Svimez, 2018; Marconi and Trapasso, 2017), we report here only a few data, extracted from the OECD (2020) and European University Association (EUA, 2020a) ${ }^{1}$.

In the period 2008-2018 public funding went from 7,5 billion euros to 7,3 in nominal values, corresponding to a contraction in real terms of $14,4 \%$ (an overall cumulative cut of 5,5 billion).

This figure places Italy among the lowest positions in the OECD countries (Fig. 1a) and it appears even more alarming when compared with the reduced share of graduates, well below the EU average (Fig.1b), and with a very high share $(25,5 \%)$ of young NEETs (young people aged 18-24 Not in Education, Employment or Training), the worst within OECD, after Turkey.

The contraction of public resources was accompanied by an increase in private resources and in student taxation which reached $30 \%$ of total funding in 2018 (Anvur, 2018), against a decrease in services and scholarships (Eurostudent, 2018) ${ }^{2}$.

In the same timeframe (2008-2018) the number of the students enrolled in the tertiary education (iscritti) $^{3}$ decreased, for the first time in the history of Italy. After the record figure of 1,8 million in 2008, they began to shrink, dropping to 1,7 million in 2019 , with a negative peak in 2015 (1.654.680 students). The students enrolled for the first time (immatricolati) show a partially similar trend. They fell sharply between 2008 and 2015 (-23 thousand), then slowly recovered, with an acceleration in the last 2 years.

\footnotetext{
${ }^{1}$ See also the OECD database online https://stats.oecd.org/ and the interactive tool available on the website of the EUA's Public Funding Observatory http://efficiency.eua.eu/publicfunding-observatory.

${ }^{2}$ According to the Union of university students (UDU, 2018), the contribution of families experienced a variation of $17 \%$ between 2008 and 2015.

${ }^{3}$ According to the MIUR student registry, all students enrolled at the university are defined iscritti, while the term immatricolati
}
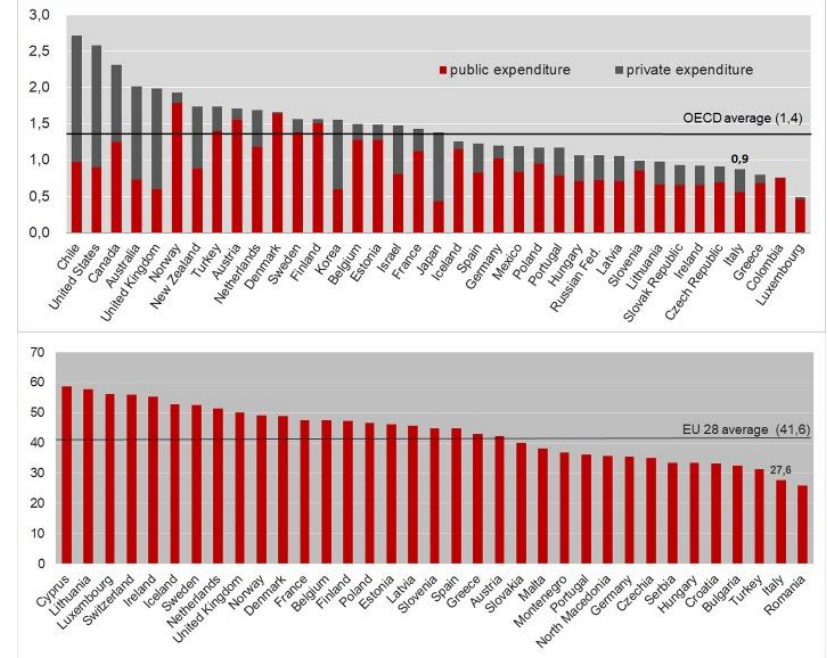

Figure 1 . Revenue shares to the university system in Italy by souce (\% GDP) in 2017 (a) and share of graduates (30-34 years) in 2019 (b). Source: OECD, 2020 (a) Eurostat (b)

A contribution to this recovery (very different on a regional scale) derives from the institution in the academic year 2017-18 of a no-tax area for students from the poorest families ${ }^{4}$, which, undoubtedly, improved school-touniversity transition rates.

Also, the academic staff experienced a radical downsizing, due to the prolonged block of turnover and the new recruitment rules introduced in 2012. Academic staff contracted by $17 \%(-13,000$ units $)$ in the $2008-2019$ period, whereas the technical administrative staff by $26 \%$ (-14,000 units). Conversely precarious positions multiplied, as reported by the Italian $\mathrm{PhD}$ students and PhDs Association (ADI, 2019)

International comparative data clearly show the divestment on tertiary education (Fig. 2).

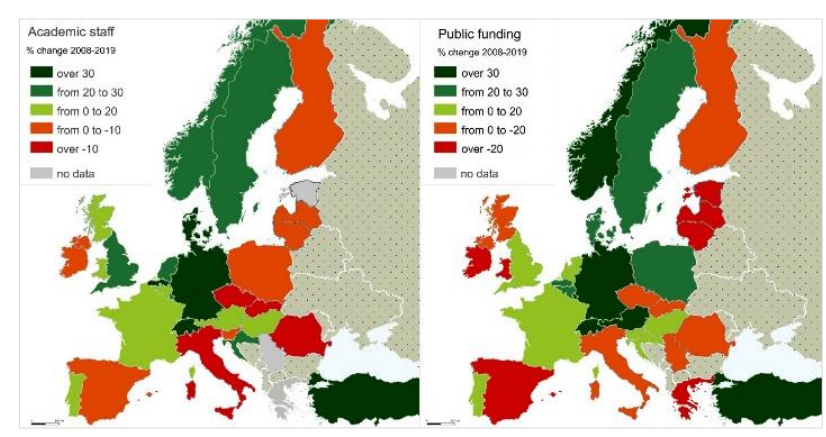

Figure 2. \% Change 2008-2019 in the academic staff (a) and public funding (b). Source: elaboration by the author on EUA data

indicates the students enrolled for the first time in a universitylevel course in any Italian institution.

${ }^{4}$ With the Covid emergency, the no-tax area has been increased. 165 million euros were allocated for this purpose, a figure equal to just over $10 \%$ of all student fees. Nonetheless, the effects of this measure have been positive, especially in universities in the South, where enrollments have started to grow again. 
Italy ranks in the tail group among the members of the European University Association (EUA, 2020a, 2020b) for the decrease in academic staff $(-17 \%)$ and public spending $(-14,4 \%)$. In the same period, Germany increased public funding by $35 \%$ ( +31 billion euros), academic staff by $46 \%$ and students by $45 \%$.

\section{The growth of internal gaps}

The negative trends observed on a national scale exhibit a sharp heterogeneity at regional and macro-regional level, with a much greater contraction for universities in the South and Central Italy, but also in those located in peripheral areas of the North.

Figure 3 shows the data relating to immatricolati. In the period 2008/09 - 2018/19 the South loses over 5 thousand students enrolled for the first time, the Islands 7 thousand, while the North and the Center register an increase in enrollments of 7 thousand and 18 thousand units.

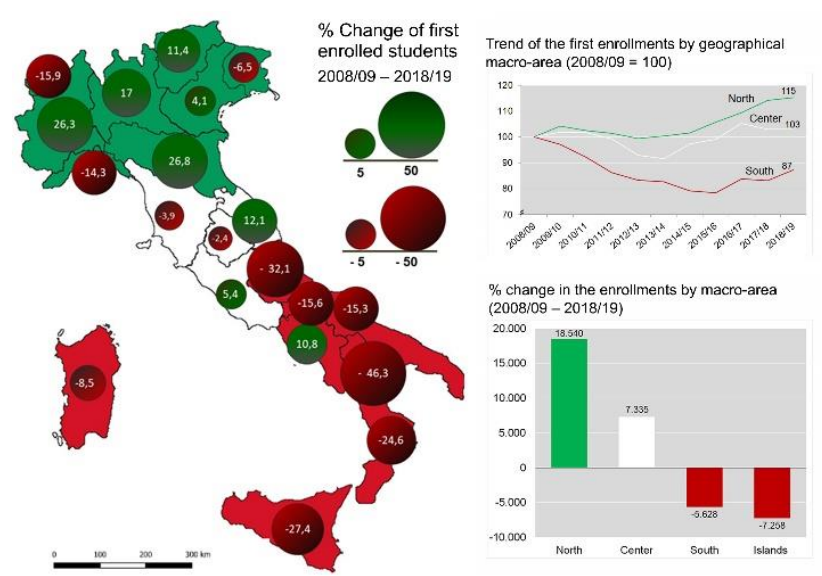

Figure 3. \% Change in first time enrollments in the period 2008/09-2018/19. Source: elaboration by the author on MIUR/MUR-National Student Registry (ANS) data

By disaggregating data at a regional scale, greater variability emerges (Fig. 3). Two regions of the Center (Toscana and Umbria) and three regions of the North (Valle D'Aosta, Liguria and Friuli) show negative values, but it is the South the most affected area. Basilicata loses almost half of enrolled students, Abruzzo more than 32\%, followed by Sicilia $(-27,4 \%)$ and Calabria $(-24,6 \%)$. The losses of the other Southern regions are more contained, but still considerable. The only exception is Campania with a positive variation of $10,8 \%$.

Several factors contribute to these trends. The first concerns the demographic dynamics and, specifically, the contraction of the younger age groups. The decline in the population aged 18-20 is concentrated in the South, which records a reduction of $11,7 \%$ in the period 2012-2019, against a positive variation in the Center $(+1,6 \%)$ and in the North $(+7,7 \%)$. A second reason is related to the transition rates from school to university, which in
Southern Italy decline much more than in the rest of the country (MIUR, 2016). The third and most worrying driver is connected to the growing student mobility, a mobility which is extremely selective both from a territorial and a social point of view.

Most of the flows originate from the Mezzogiorno. In the academic year 2017-18 over 24 thousand Southern students, equal to about a quarter of the total, enrolled for the first time in a university outside the macro-region of residence (Anvur, 2018). This is a much higher value than the national average and, moreover, it is growing strongly in relative terms, due to the overall decline in enrollments in the South. This share is even larger if we consider the outflows of students with a BA (laurea triennale) enrolling in master's degrees (laurea magistrale) in a university located in the Center-North (about one southern student out of 3 in 2018).

High outward mobility flows are not matched by significant inward mobility ones: less than $3 \%$ of students enrolled in a Southern institution come from the other two macro-areas.

By looking at mobility flows by region (Fig. 4), Puglia and Sicilia record the greatest losses, but negative balances also appear in Northern regions (Veneto, Liguria, Valle d'Aosta) and in the Center (Umbria). Conversely, EmiliaRomagna, Lombardia and Lazio exhibit very positive results. However, over time, this latter region features a decline in terms of attractiveness, whereas Piemonte and Lombardia feature a growth rate compared with their share in 2003-04 (Fig. 4).

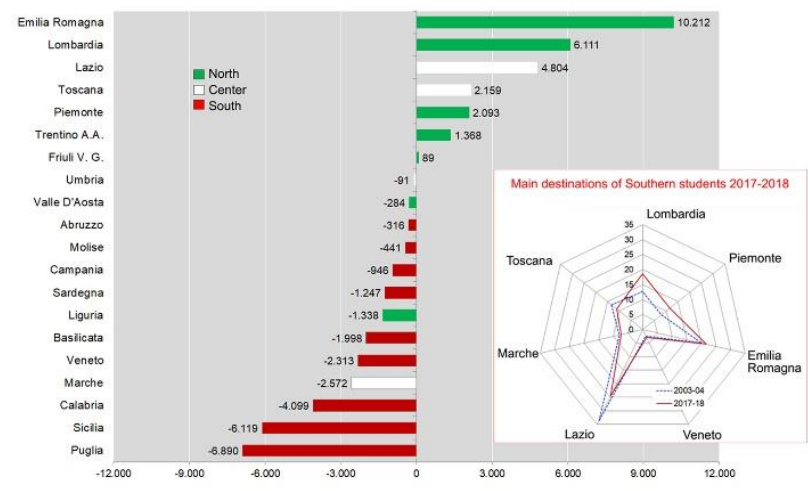

Figure 4. Net migration balance of enrolled students by region in 2017-18 (a) and main destination of Southern students (b). Source: elaboration by the author on Anvur data, 2018.

The intensification of this one-way South-North mobility produces significant impacts. A recent survey by Coluccia e Ortolano (2018), provides a rough but significant estimate of the loss of resources that these mobility flows represent for the Southern university system. Using the standard cost per student ${ }^{5}$ the authors obtain an estimate of one billion euros per year lost in the Mezzogiorno, due to the enrollment in the Center-North of residence of 153
${ }^{5}$ For the base quota calculation, a highly discussed algorithm has been used (see Banfi and Viesti, 2016; Cappelletti Montano, 2016). The irregular students who are over a year late in their academic career are not included: an arbitrary choice that punishes hardly the universities located in economically, socially and infrastructurally disadvantaged contexts. 
thousand southern students (with reference to the year 2016-17). Adding to this figure the private consumption expenditure activated by students in the destination regions, calculated at 2 billion per year, they came to estimate an overall loss of 3 billion per year in the South. And this without considering the indirect effects on local employment.

The transfer of economic resources along the South-North route is only the first order impact. By delving deeper into the migration pattern an even more distressing effect arises: the depletion of the quality of human capital in Southern regions. Indeed, studies by Almalaurea (2020) and Banca d'Italia (2016; De Angelis et al., 2016) show that students leaving southern regions to study elsewhere are young (over $90 \%$ of the total outgoing flow is under twenty years) and with an educational background better than those who stay (over $72 \%$ have a high school license and the diploma grades are on average higher).

Given its relevance, the phenomenon of student mobility has been the subject of growing interest from the scientific community and studies dedicated to identifying its determinants have multiplied (Fiorentino, 2015, Svimez, 2018; Ferrara and Nisticò, 2018). A review of the literature developed on the subject is beyond the scope of this paper. However, it is worth noting that the choice of mobility can hardly be read as a completely free choice (Cersosimo et al, 2018; Iovino, 2017; Viesti, 2019a). The attractiveness of Southern universities (as well as those located in peripheral areas of the Center North) is influenced by very difficult context conditions, concerning labor market, future salary prospects, quality of life, support and services for students, the accessibility of the study institution. All conditions that are largely independent of the quality of the local governance.

Undoubtedly, student mobility contributes to weakening the universities located in the weakest and most peripheral areas: a smaller number of students inevitably translates into a decrease in student tuition and into a contraction in state transfers.

In this respect, the introduction of a new allocative mechanism for the distribution of the ordinary fund (FFO) has accelerated the polarization process and deepened the divergences between territories and institutions.

Starting from 2009, the FFO has been split into a base share (quota base) $)^{6}$ and a reward share (quota premiale) to be assigned to each institution. It was established that the first source would be decreasing over time, both in absolute terms and as percentage share, whereas the

\footnotetext{
${ }^{6}$ Since 2014 , the base quota has been allocated partly on the basis of past spending trends and partly on the basis of the "standard cost per student", while the reward quota has been allocated according to some criteria measuring the quality in teaching and research by the single institution. In 2020 the reward quota has been allocated as follows: $60 \%$ for the results of the VQR assessment measured through a research index (IRFS), $20 \%$ for the quality of recruitment policies as measured by the scores in the VQR obtained by the newly recruited and promoted academic staff (IRAS2). The remaining 20\% based on quality indicators and internationalization of didactics.
}

second would gain a growing weight over time (from $7 \%$ in 2009 to $27,2 \%$ in 2020), up to cover $30 \%$ of the total funding to each university ${ }^{7}$.

After the drastic cuts implemented in the years 2008-2016, the FFO has started to grow again, although the increase mainly concerns the reward quota, the so-called risorse finalizzate (targeted resources) and some non-structural items. The base quota has continued to decrease (covered $54 \%$ of the entire FFO in 2020 compared to $72,5 \%$ in 2014), putting at risk the survival of some institutions, unable to cover staff costs, which is considered by its nature a fixed cost and hence cannot be reduced.

It is not possible here to focus on the allocative mechanism and the "merit" indicators used to redistribute the FFO among the different universities. However, some elements deserve to be mentioned: 1) the choice to allocate a part of FFO on the basis of a reward quota does not find comparisons in any other European country, except for the United Kingdom. It has been taken against recommendation by EUA (Claeys-Kulik and Estermann, 2015), where the commitment of exclusively additional resources to the reward quota is proposed, in order to avoid the adverse impacts, such as increased competition, volatility of funding, and similar issues; 2) most of the data on which the performance indicators are built comes from the graduate program evaluation and accreditation system (AVA) and from the results of research evaluation exercises (VQR), much debated in methodologies (Baccini and De Nicolao, 2016; Prota and Grisorio, 2016) and in the impacts (Cassese, 2013; Turco, 2017); 3) the indicators measuring the quality in teaching and research exhibit a very high variability over time ${ }^{8}$ and, moreover, they are spatially blinded, i.e. indifferent to the context conditions (Iovino, 2017, 2021).

In short, they have been built to enhance the differences among institutions and to measure the absolute levels of performance achieved by the universities, rather than the results obtained with respect to the resources given.

Figure 5 shows the variation of the ordinary fund (FFO) between 2008 and 2020 by geographical macro-region, by region and by mega universities (over 40.000 students) ${ }^{9}$.

In a territorial perspective, the polarization effects are evident: an important slice of the meager financial resources has moved in recent years to the North, towards a small number of "deserving" institutions, concentrated mainly in 4 regions (Piemonte, Lombardia, Veneto and Emilia-Romagna).

${ }^{7}$ Beyond the base quota and the reward quota, the national fund FFO also includes a compensating quota for the universities located in less developed regions (2,2\% of the FFO in 2020).

${ }^{8}$ Between 2008 and 201522 different indicators were used and variously weighted. Many of them have been constructed in such a way that the variability among institutions results artificially increased by an arbitrary choice of the scale of measurement (Viesti, 2016, Prota and Grisorio, 2016).

${ }^{9}$ Only State institutions are taken into consideration, except for high schools with special regulations. 


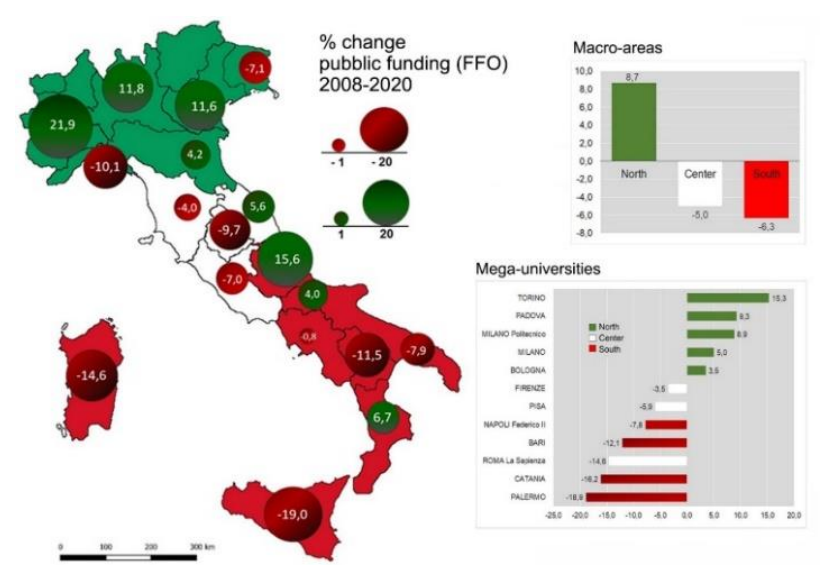

Figure 5. \% Changes in the national funding (FFO) 2008-2020. Source: elaboration by the author on MIUR/MUR decrees

Despite the safeguard clause ${ }^{10}$, the funding reduction has severely hit the South, especially the Islands (-6.3\%), but also the institutions in the Central have lost $5 \%$ of resources $(-94,8 \mathrm{mln} €)$. A trend that becomes even more pronounced in the 12 Italian mega-universities (over 40 thousand students), with Torino $(+15,3 \%)$ and Palermo ($18,9 \%$ ) in the opposite sides of the rank.

\subsection{A classification of regional university systems}

Revisiting the taxonomy developed by the EUA Public Funding Observatory (2017) for the European countries, we propose a classification of Italian regional tertiary education systems in 6 different types. These categories are obtained by crossing the previously examined variables, i.e., the percentage variation of enrolled students and FFO in the period 2009-2019.

The graph in Figure 6 shows the positioning of the different regions. In the first quadrant we find the growing systems, characterized by an increase in both indicators. In this context, it is possible to make a further distinction. On one side lies the university system of Lombardia that we can define as frontrunner, as it is characterized by a greater growth in FFO than that of enrolled students. On the other side, there are the systems of Piemonte, Emilia-Romagna and Marche, marked by a growth in students higher than that of the FFO and, therefore, labeled as growing systems under pressure.

In the second quadrant we find the systems in transition, characterized by a growing FFO and a decrease in students. It includes Abruzzo, Calabria, Molise and Veneto. In the time interval considered, the university systems of these regions have lost their attractiveness, but it is likely that, thanks to the stability of the resources allocated, they will be able to transit towards the $1 \mathrm{st}$ quadrant in the short run.

The third quadrant includes regions with declining university systems, where both FFO and students decrease. Also in this case, we can distinguish between declining systems in which the contraction of resources is greater than students decrease (Umbria, Toscana and Sardegna) and systems under pressure where the opposite occurs.

Finally, in the fourth quadrant fall the systems in danger, marked by a gap between supply and demand, with a negative variation in financial resources and a positive change in students. This the case of Campania, Lazio e Liguria penalized by the FFO despite the increase in students.

The map (Fig. 6) shows clearly how "healthy" systems are strongly polarized in Northern Italy, especially in the triangle formed by Lombardia, Piemonte and EmiliaRomagna. In the Center, Marche records the best performance.

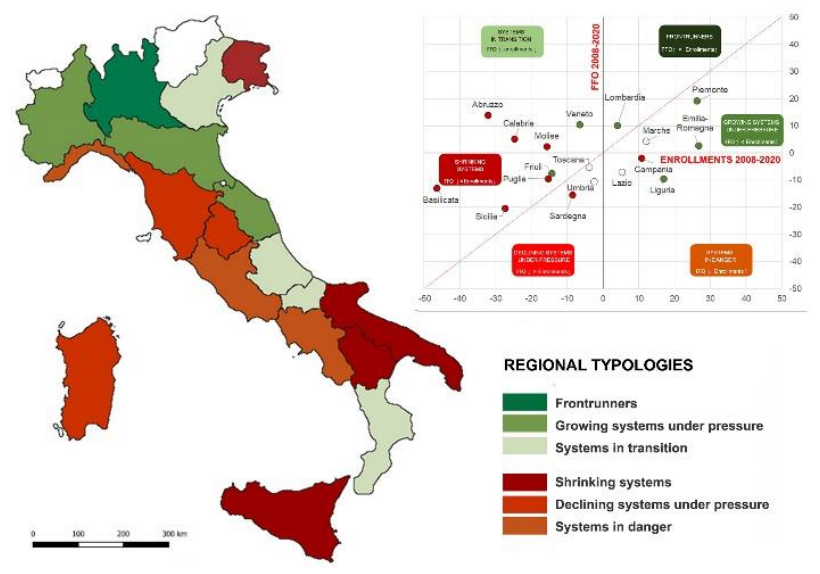

Figure 6. A taxonomy of regional university systems in Italy. Source: elaboration by the author on EUA data.

\section{A focus on recruitment policies and departments of excellence}

Geographical polarization of the tertiary education system has also been exacerbated by recruitment policies.

The MIUR (MUR since 2020) annually establishes the allocation of human resources (teachers and administrative technical staff) to universities, through the use of punti organico PO (notional units for recruitment), a benchmark of personnel costs ${ }^{11}$.

After 5 years in which recruitment of new human resources was simply banned, Legislative Decree 49/2012 admitted the possibility of new hiring under some conditions.

The first condition concerns the establishment of limits on turnover. To maintain equilibrium conditions, the whole system should have a turnover of $100 \%$, i.e. obtain a number of PO equal to retirements, a condition satisfied since 2018 at the national level, but not at the local scale. According to the decree, each institution is entitled to only $50 \%$ of PO deriving from retirements but it can obtain "additional PO" (even higher than its turnover), competing with other universities (second condition).

10 The safeguard clause, which is part of the equalization quota (175 mln $€$ in 2020), tops the cut in the FFO at the level of the single institution at $2 \%$ compared to the level obtained in the previous year.

${ }^{11}$ Punto organico (PO) is the unit of measurement used to define the annual number of recruitments that can be made by each institution. 
The criteria of "merit" used for this redistribution of resources among institutions are based on two financial indicators: an indicator of the academic staff expenditure (given by the ratio of total outlays for wages to employees to the total revenue) and an indicator of economic and financial sustainability (ISEF), which compares the total revenue and the expenses of the university.

Based on these indicators only the institutions qualifying as "virtuous" 12 are granted extra resources (PO) in proportion to the financial soundness. Hence, the better the financial situation of an institution is, larger resources are assigned for recruitment.

The principles underlying this allocative mechanism are apparently correct for the aim of providing incentives to the governance of the institution. However, two aspects deserve to be highlighted for their iniquity. The first is the inclusion of revenues obtained from students' fees by each university as a source of financial virtue (Viesti, 2019b). This has clear territorial implications: universities in richer areas can count on higher fees than institutions operating in less rich areas. As reported by the UDU (2018), one of the perverse effects of this mechanism was the generalized increase in student fees ${ }^{13}$. Similar arguments can be used to understand the polarizing effects of the decision to include "other revenues" (from foundations and local public bodies) in the computation of the index of financial health of each institution (ISEF). This automatically makes the budget of universities in richer areas more "virtuous", independently of the quality of its governance.

Figure 7 clearly shows the effects of territorial disparities of this allocation system. Funding (FFO) and punti organico (PO) reinforce each other and, by so doing, they push the system towards a widening of the divergences.

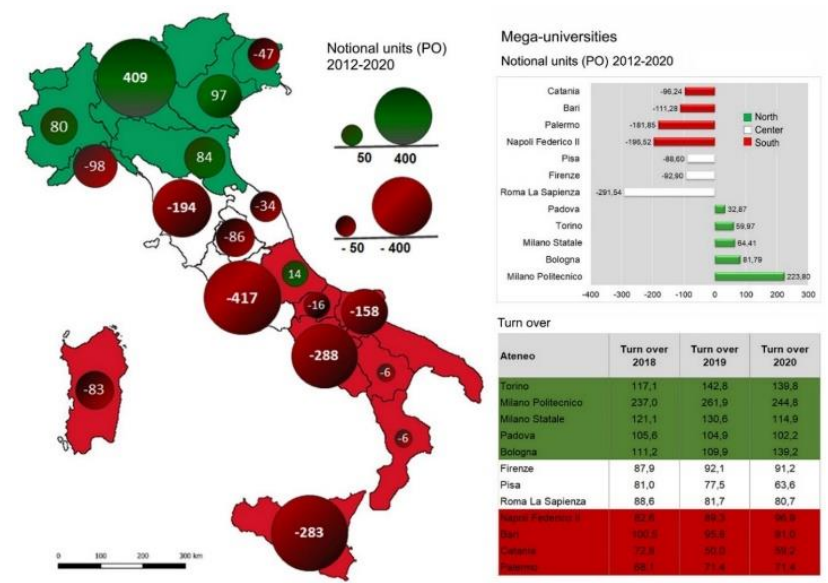

Figure 7. Resources for recruitment in terms of notional units (punti organico, PO) 2012- 2020 by regions and megauniversities. Source: elaboration by the author on MIUR/MUR decrees

12 They must satisfy the following criteria: 1) a share of total expenditure over total revenues less than $80 \%$, a value of ISEF less than 1.

13 Presidential Decree 306/1997 (art. 5) requires universities to have a student contribution not exceeding $20 \%$ of the FFO. Subsequent changes excluded first irregular students and then
In the period 2012-2020 the South and the Center lose 872 and 730 PO respectively, while the North, earns 524 PO, an enormous figure if we consider that it allows the hiring of 1.049 researchers. Lombardia and Lazio are at the extremes of the ranking, the first with a positive variation of 409 PO, the second with a loss of 417 points. In the Southern regions, Campania and Sicilia display the greatest losses. At the institutions level, the asymmetries are even greater, as shown in the table referring to the 12 Italian mega-universities. Against a national turnover of $100 \%$, the Politecnico of Milano records a turnover of $237 \%$ in $2018,261 \%$ in 2019 and $244,8 \%$ in 2020 . All the mega-universities in North exceed the threshold of $100 \%$, while all those in the Center and in the South record a turnover below the threshold, with minimum peaks in the Islands.

It is a transfer mechanism fostering cumulative and polarizing effects: more teachers, larger supply of courses, more students, larger revenues (deriving from taxation and the increase in the FFO) ${ }^{14}$, greater economic and financial sustainability, more points staff assigned and so on.

Another important driver of change in the tertiary education system came from the establishment since 2018 of a new award funding mechanism aimed to the so-called Departments of Excellence (L.232/2016).

By overcoming the principle of autonomous decision making by local governance structures, the provision directly grants 1,5 billion in 5 years to 180 Departments, selected on the basis of a standardized indicator of departmental performance (ISPD), elaborated by Anvur in order to measure and compare the results obtained by each department in the VQR.

Beyond the critical issues (errors and limits of the algorithm used for the calculation of the ISPD, lack of confrontation and democratic legitimacy, etc.) reported by several authors (Baccini, 2017; Bertoli-Barsotti, 2017), this decision has great territorial implication.

The allocation of such a large sum to few selected Departments is inevitably destined to have a deep and potentially devastating impact on the geography of the Italian tertiary education system, increasing the inequalities between institutions.

Figure 8 shows the territorial asymmetries in the distribution of the Departments of Excellence. The North with 106 Departments grabs 59,7\% of the resources, against $26,5 \%$ of the Center and just $13,8 \%$ of the South. In the city of Milano alone, the number of excellent Departments is almost equivalent to that of the whole Mezzogiorno (20 vs 25).

Overall, the cumulative effects prompted by this allocation can only be expected to foster the geographical polarization of the whole system. After 5 years of extra

the international students. The rule was disregarded in the period 2009-2015 especially in Southern Italy (UDU, 2018).

${ }^{14}$ Recruitment policies also account for $20 \%$ of the FFO reward share, due to IRAS2, the qualitative-quantitative indicator aimed at measuring the scientific production of recruited academic staff. 
resources (which can also be spent on the recruitment of new researchers) the Departments of Excellence will be able to increase the distance, in terms of scoring, from the other departments. This will ensure not only an increasing share of the FFO, but also greater future access to these provisions if the exercise will be repeated.
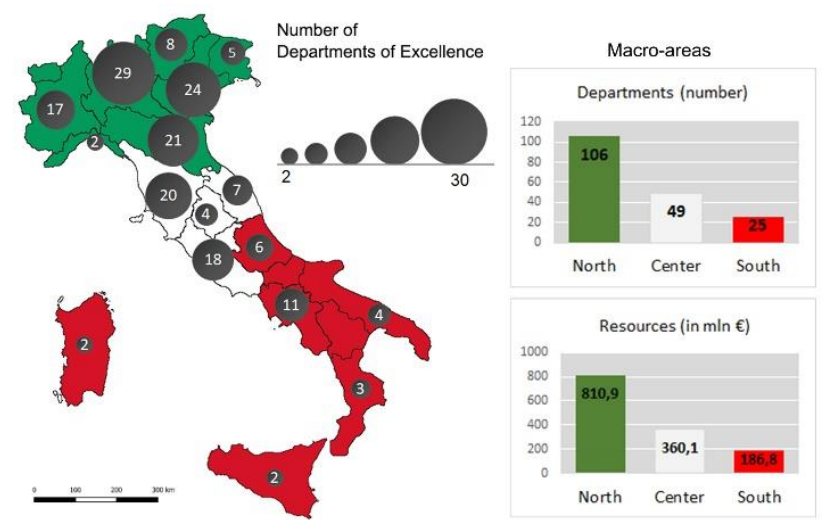

Figure 8. The geography of the 180 departments of excellence Source: elaboration by the author on MIUR/MUR data

In any case, the initiative will inevitably produce the decline of many departments located in the most peripherical areas that will hardly be able to recover the gap for to the establishment of a poverty trap: fewer resources, less possibility of investing in academic staff and infrastructures, lower quality of research, fewer resources, less students, and so on, in a vicious circle that can only lead- in a short time- to cancellations of courses, departments and universities.

\section{Concluding remarks}

Policy choices regarding tertiary education have induced in the last decade a large contraction in the size of the whole university system and its geographical polarization, in the presence of already large and lasting disparities in comparison to other countries in the European Union and in the OECD area.

In the context of an economic recession, a strong competition among universities has been promoted, a competition aimed not at identifying and rewarding excellence with additional resources, but rather at redistributing, with a clearly sanctioning approach, heavy budget cuts.

This redistributive process has taken place through the introduction of a national assessment of the performance of each single institution based on indicators and allocation procedures that are questionable in many respects.

The evaluation processes and reward criteria implemented has resulted in dynamics of selective reduction of resources on a territorial basis, with a strong polarization of funding, academic staff and students in a small number of institutions located in the richest and most dynamic regions of Northern Italy.

Without denying the role of an often-inadequate local governance and managerial practices in many universities that can have contributed to geographically polarizing process over the decades, we believe that national policies have been crucial in fostering these divergent dynamics.

Rather than investing on the infrastructure for a knowledge-based economy as in Germany and France and other EU countries, the choice has been to drain the already meagre resources dedicated to tertiary education in a process of redistribution from weaker universities to stronger ones. In practice, a top-down approach to the reform has been used in order to implement a managerial model inspired by large universities in the Anglo-Saxon world, a model whose general value has been questioned lately (Sayer, 2015; The Economist, 2015). A system based on "meritocratic" indicators and allocation criteria, aimed at rewarding or punishing the performance of universities, without connecting the results achieved to the context conditions.

The impact that the university produces on regional development has been totally neglected, allowing the marginalization of most of the Southern universities, but also of a large part of those in central Italy and the more peripheral Northern regions (Liguria and Friuli). A choice of policy, which runs the risks of producing irreversible damage to the economic and cultural development of the whole country. The impacts on the level of social and territorial mobility are equally serious, as access to education appears to be increasingly governed by a selection mechanism based on wealth. In other words, a strongly inequitable system has been built both from a social and territorial point of view.

Within such a bleak scenario, some small positive signs, nevertheless, deserve to be noted: 1) the recovery of enrollments, which continued even in full pandemic emergency $(+6 / 7 \%$ in 2020 , according to preliminary data), with a good performance of Southern universities; 2) the expansion of the no tax area and the increase in scholarships offered to students, although below comparable levels in countries of similar levels of development; 3) the growth of the FFO $2020(+€ 365$ million, $+4.6 \%$ ) which exceeded in nominal terms its maximum peak in 2009 ; 4) the increase in teaching staff, due to the extraordinary recruitment plan for junior researchers on a tenure track (type B researchers); 5) the modification of the safeguard interval, which for the first time produced a strictly positive variation of between 0 and $4 \%$ of resource funding (i.e. no university loses resources compared to 2019).

However, the underlying architecture did not change. Despite the pandemic emergency, all the trends of the last decade are found in recent regulatory interventions (see the DM FFO 2020 and the new VQR exercise): the increase in the reward component to the detriment of the base quota, the imposition of a fiercely competitive managerial logic, the adoption of a system of indicators that enhances differences and rewards excellence, regardless of the context and starting conditions.

Increasing the quality of a few excellent universities, pushing others towards decline is, in our opinion, a shortsighted choice. A choice that separates the Italian system from the spirit and objectives of inclusion and socio- 
territorial equity of the 2030 Agenda and frustrates the efforts made by the EU to promote, through a place-based cohesion policy, the balanced and harmonious development of the European territory.

In our view investing on a network of smaller universities well distributed on the territory is better suited for a country where the urban distribution is made up of small provincial cities of old tradition and good economic record and where the backbone of the industrial structure is mainly made of small medium enterprises. In this perspective, the recent experience of research assessment and evaluation exercise could still be used to develop a system of rules and incentive schemes that can improve the use of public resources in the tertiary education system but, at the same time, take in due account the contextual factors that make the work harder for institutions located in disadvantaged contexts.

\section{References}

ADI- Associazione dottorandi e dottori di ricerca in Italia, (2019). VIII Indagine ADI su Dottorato e Post-Doc, Roma, 8 maggio.

AlmaLaurea (2020). XXII Indagine - Profilo dei Laureati 2019. Rapporto 2020. Consorzio Interuniversitario AlmaLaurea, Bologna.

Anvur (2018). Rapporto biennale sullo stato del sistema universitario e della ricerca 2018. Roma.

Anvur, (2016). Rapporto biennale sullo stato del sistema universitario e della ricerca 2016. Roma.

Baccini, A. (2017). Ludi dipartimentali, ecco i vincitori: $87 \%$ dei fondi al Centro-Nord. De profundis per il Sud. 18 maggio, http://www.roars.it/

Baccini, A., De Nicolao, G. (2016). Do they agree? Bibliometric evaluation versus informed peer review in the Italian research assessment exercise. Scientometrics, 108, 3, pp 1651-1671.

Banca d'Italia (2016). L'economia delle regioni italiane. Dinamiche recenti e aspetti strutturali. Roma.

Banfi, A., Viesti G. (2016). Il finanziamento delle università, in Fondazione Res, op.cit., pp. 329-368.

Bertoli-Barsotti, L. (2017). Le incongruenze dell'ISPD e i dipartimenti di eccellenza, 3 agosto http://www.roars.it

Cappelletti Montano, B. (2016). Gli effetti perversi delle formule dei costi standard. 18 gennaio, http://www.roars.it

Cassese, S. (2013). L'Anvur ha ucciso la valutazione, viva la valutazione. il Mulino, 1, pp. 73-79.

Cersosimo, D., Nisticò, R., Pavolini, E., Prota, F., Viesti, G. (2018). Circolazione del capitale umano e politiche universitarie: un'analisi del caso italiano. Politiche Sociali, n.3, pp.387-406.

Claeys-Kulik, A.L., Estermann, T. (2015). Define Thematic Report. Performance-Based Funding of Universities in Europe. European University Association, Bruxelles.

Coluccia, F., Ortolano, P. (2018). Analisi di impatto locale dell'emigrazione studentesca. Rivista economica del Mezzogiorno, n. 3, pp.559-576.

De Angelis, I. Mariani, V., Modena, F., Montanaro, P. (2016). Immatricolazioni, percorsi accademici e mobilità degli studenti italiani. Banca d'Italia, Questioni di Economia e Finanza (Occasional Papers), 354, Roma.

EUA- Public Funding Observatory (2020a). Report 2019/20. February.
EUA-Public Funding Observatory (2017), Report 2017. December.

EUA-Public Funding Observatory (2020b). Country sheets. February.

Eurostudent (2018). Ottava indagine Eurostudent. Le condizioni di vita e di studio degli studenti universitari 2016-2018. Roma.

Ferrara, A.R., Nisticò, R. (2018). La mobilità degli studenti universitari in Italia. Rivista economica del Mezzogiorno, n. 12, pp. 117-138.

Fiorentino M. (2015), La questione meridionale dell'università. Editoriale scientifica, Napoli.

Fondazione Res (2016). Università in declino Un'indagine sugli atenei da Nord a Sud. (G. Viesti ed), Donzelli, Roma.

Iovino, G. (2017). "Si salvi chi può". Mobilità studentesca e squilibri socio-territoriali nel processo di accumulazione del capitale umano in Italia, in Dansero, E., Maria Lucia, G., Rossi, U., Toldo, A. (S)radicamenti, Società di studi geografici. Memorie geografiche, NS 15, pp. 57-68.

Iovino, G. (2021). "Feedback University" Il peso della valutazione e dei ranking sul ridisegno della geografia universitaria italiana, (forthcoming in Memorie geografiche, NS 19).

Marconi, G., Trapasso, R. (2017). L'Università italiana nel contesto internazionale: i dati OCSE. Rivista economica del Mezzogiorno, 3, (numero monografico L'Università nel Mezzogiorno), pp.565-583.

MIUR - Ufficio Statistica e Studi (2016). Focus "Gli immatricolati nell'a.a. 2015/2016 il passaggio dalla scuola all'università dei diplomati nel 2015". marzo.

OECD (2020). Education at a Glance 2020. Oecd Indicators. Paris.

Prota, F., Grisorio, M.J. (2016). La qualità della ricerca. in Fondazione Res, op.cit., pp. 253-287.

Sayer, D. (2015). Rank Hypocrisies: The Insult of the REF. Sage, Los Angeles.

Svimez (2018). Rapporto Svimez 2018. L'economia e la società del Mezzogiorno. il Mulino, Bologna.

The Economist (2015). Excellence vs. Equity. Special Report Universities. 28 marzo.

Turco, A. (ed) (2017). Culture della valutazione. Carocci editore. Roma.

UDU - Unione degli universitari (2018). Atenei fuorilegge. Dossier 2018. Roma.

Valero, A., Van Reenen, J. (2016). The Economic Impact of Universities: Evidence from Across the Globe. London School of Economics, CEPR Discussion Paper, 1444.

Viesti, G. (2016). Il declino del sistema universitario. in Fondazione Res, op.cit., pp. 3-56.

Viesti, G. (2017). Il sistema universitario italiano in comparazione internazionale, in Pizzuti F.R. (ed), Rapporto sullo stato sociale 2017, Roma, Sapienza University Press.

Viesti, G. (2019a). Un'analisi della mobilità geografica degli studenti universitari in Italia. Rivista economica del Mezzogiorno, 2, giugno, pp. 439-461.

Viesti, G. (2019b). Le politiche universitarie. Sinappsi, IX, n.3, pp. 94-105.

Visco, I. (2014). Investire in conoscenza Crescita economica e competenze per il XXI secolo. il Mulino, Bologna. 